\title{
ANÁLISIS SIMBÓLICO Y ESTADÍSTICO DE LAS VENTANAS EN LA POESÍA DE WIDAD BEN MUSA
}

\author{
Encarnación Sánchez Arenas \\ Universidad de Sevilla \\ encarnacion.sanchez.arenas@gmail.com \\ https://orcid.org/0000-0002-0704-2073
}

\begin{abstract}
RESUMEN: Se aporta un estudio simbólico de las ventanas en Widad Ben Musa, basado en diferentes diccionarios de símbolos, y un estudio estadístico basado en dos obras fundamentales: $1^{\text {a }}$ ) «Frecuencias y dispersión léxicas en textos médicos divulgativos en español» (2015) de Leonardo Campillo Llanos e Hiroto Ueda; $2^{\mathrm{a}}$ ) La poesía de Luis Cernuda. Estudio cuantitativo del léxico de "La realidad y el Deseo» (1973) de Juan Alfredo Bellón Cazabán.

PALABRAS ClAVE: Widad Ben Musa, poesía marroquí contemporánea, las ventanas, simbolismo, estadística.
\end{abstract}

\section{SYMBOLIC AND STATISTICAL ANALYSIS OF THE WINDOWS IN THE POETRY OF WIDAD BEN MUSA.}

ABSTRACT: A symbolic study of the windows by Widad Ben Musa is provided, based on the assortment of dictionaries of symbols, and a statistical study based on two fundamental works: 1) «Frecuencias y dispersión léxicas en textos médicos divulgativos en español» (Frequencies and lexical dispersion in informative medical texts in Spanish), (2015) by Leonardo Campillo Llanos and Hiroto Ueda; 2) The poetry of Luis Cernuda. Quantitative study of the lexicon of "La realidad y el deseo» (Reality and desire) (1973) by Juan Alfredo Bellón Cazabán.

KEYWORDS: Widad Ben Musa, contemporary Moroccan poetry, the windows, symbolism, statistics.

\section{DATOS BIOGRÁFICOS}

Esta poetisa marroquí nace el 9 de noviembre de 1969 en Alcazarquivir (al-Qasr al-Kabir/Ksar Kbir) (Del Amo, Marsá y Ortega, 2008: 113-114), donde pasa su infancia y juventud. En 1976, cuando contaba 7 años, Widad se incorpora a la escuela «alSadrawi», cuyo director era su padre. Allí traba una relación directa con la palabra y la letra y se enamora de la lengua árabe. Su primer texto se publicó, cuando tenía solo 11 años, en el periódico al-Mitaq al-Watani. Tras eso pasa a la etapa de publicar con asiduidad en otros periódicos nacionales como al-'Alam, al-Ittihad Istiraki y al-Bayan.

En 1992, a los 23 años, se matricula en la Universidad de Fez para estudiar Derecho, cursando dos años en Fez y uno en Rabat. El 15 de agosto de ese mismo año contrae matrimonio, instalándose en Rabat. De ese matrimonio nacen sus dos hijos, Maryam y Nizar, a los que dedicará su poemario Entre dos nubes (2006). Pero Widad acabará divorciándose en 2007. Por otro lado, en 1993 se produce el fallecimiento de su madre, a quien dedicará su primer poemario, Tengo una raíz en el aire (2001). Al 
instalarse en Tánger, en 2006, trabaja como directora del centro cultural Ahmed Bukmagh (Ahmad Bu Kamaj).

Deseaba conectar con los otros, según su expresión, a través del poema y de la acción cultural, entrevistando a varios personajes en su actividad como presentadora del programa «Trayectorias» (Masarat) y del programa «El balcón cultural» (al-Surfa altaqafiya), en el canal Midi 1. Además, se ocupa de la prensa, escribiendo columnas en la revista de papel Express (al-Hisbris) y es miembro del Comité Ejecutivo de la Unión de Escritores de Marruecos y secretaria de sus finanzas; así como miembro del comité asesor de la Casa de la Poesía (Bayt al-si 'r) de Marruecos, en la que había trabajado antes como asesora encargada de las relaciones públicas, y en la oficina del director de la Casa del Arte Moderno (Bayt al-Fann al-Mu'asir) como delegada de jefatura en Biris, de Asila. Trabaja como jefa de la sección cultural del periódico al-Yarida al-Ulà, y como periodista en el periódico al- 'Alam.

En 2006 publica su poemario de las ventanas, Las abrí a ti, y en 2010 publica Estuve a punto de perder mi narcisismo. El 17 de septiembre de 2011 Widad vuelve a contraer matrimonio, con su amado Baha', al que dedica su poemario Me distraigo con esta vida (2014), así como a su padre, fallecido poco antes. Pero se volverá a divorciar en 2017.

En 2016 publica su poemario El corazón libre, que gana el premio Gutenberg en Alemania y que será expuesto en la Feria del Libro de Madrid.

El matrimonio de Widad Ben Musà ha vivido inmerso en las nuevas concepciones que han conducido a la reforma del código familiar marroquí -la Mudawwana-, con el cual, no solo se ha suprimido la supremacía del marido, sino que también se ha puesto fin, al menos legalmente, a la concepción patriarcal de la familia, igualando a ambos cónyuges al introducir en la definición del matrimonio la innovación de que la familia es responsabilidad tanto del marido como de la esposa (RuizAlmodóvar, 2007: 271).

Widad Ben Musà no solo ha trabajado y trabaja fuera del hogar, sino que, en calidad de tesorera de la Unión de Escritores de Marruecos, ha gozado de plena libertad para asistir a muchas conferencias y encuentros en América Latina, en la Casa Árabe de España sobre la escritura feminista contemporánea, en la Feria del Libro de Segovia, en el encuentro internacional sobre la prensa, medios de comunicación y libertad de expresión en Haydarabad en India, en la Feria Internacional del Libro en Túnez, en las Noches de Poesía Árabe en Argelia, en encuentros poéticos de Siria y Egipto a través de la Casa de la Poesía, junto a sus últimas participaciones, entre otras, en el Festival Internacional de Poesía en Costa Rica o firmando un convenio con la Unión de Escritores de China en un viaje realizado a este país. También está en contacto con las Uniones de Escritores Árabes de diferentes países.

Widad trabaja también como periodista en el canal Midi 1 en Tánger y prepara un programa cultural -«Caras»- que invita a pensadores y creadores en diferentes campos, presentando semanalmente un boletín cultural (Echchaoui y Sánchez, 2017: 29).

Por lo que respecta a su orientación política y sindical, Widad admite que nunca perteneció a ninguna institución de este tipo. Según nuestra autora, «la política estropea la inspiración poética» (Echchaoui y Sánchez, 2017: 6). Respecto a la religiosidad, Widad proviene de una familia religiosa por excelencia. Su abuela y sus tías recitaban todas las tardes canciones religiosas. Cada viernes era un día festivo religioso, con todos sus rituales y costumbres; comer cuscús e ir a la mezquita era imprescindible. Pero ahora Widad no reza a pesar de ser creyente (Echchaoui y Sánchez, 2017: 4). 
Las mujeres musulmanas, como Widad, valoran especialmente del Islam su dimensión espiritual. Hacen de este modo una reinterpretación de la religión heredada, realizando el tránsito de una religión hecha de prohibiciones, especialmente para las mujeres, a una religión de creencias y de espiritualidad (Touraine, 2007; Beck en Jiménez Delgado, 2012: 498). Muchas mujeres musulmanas hablan de esa espiritualidad en contraposición al Islam de la obligación y las prohibiciones (Jiménez Delgado, 2012: 497-498).

\section{SIMBOLISMO DE LAS VENTANAS}

A continuación, vamos a analizar el símbolo de la ventana que, aunque aparece de forma esporádica en varios poemarios, es el eje central de Las abrí a ti. Se realiza este estudio sobre el conjunto de los seis poemarios, referenciados en árabe y que han sido traducidos al español:

$1^{\circ}$. Binmusà, Widad (2001). Li yidr fi l-hawa'. Si 'r. Mansurat Wizarat al-Taqafa wa-1-Ittisal / Matba'at Dar al-Manahil. Rabat.

$2^{\circ}$. Bin Musà, Widad / Ben Moussa, Ouidad (2006). Bayna gaymatayni. Si 'r / Entre deux nuages. Poèmes. Ed. Bilingüe. Trad. francesa de Yalal al-Hakmawi. Editions Marsam. Rabat.

$3^{\circ}$. Binmusà, Widad / Ben Moussa, Ouidad (2006a). Fatahtu-ha 'alay-ka. Si'r wa-Suwar / Je les ai ouvertes sur toi. Poèmes \& photos. Trad. francesa y prefacio de 'Abd al-Rahman Tankul. Editions Marsam. Rabat.

4. Binmusà, Widad (2008.). Zawba'a fi yasad. Si $r$. Mansurat Marsam. Matba'at al-Nayah al-Yadida. Al-Ribat.

$5^{\circ}$. Binmusà, Widad (2010). Kidtu afqidu naryisiyati. Si 'r. Ward al-Tiba'a wa-1Nasr wa-l-Tawzi`. Dimasq.

$6^{\circ}$. Binmusà, Widad (2014). Alhu bi-hada l-'umr. Dar Tubqal li-l-Nasr. Matba'at al-Nayah al-Yadida. Al-Dar al-Bayda'.

La ventana es un umbral transparente, una abertura en una pared material que deja entrar el aire, la luz del sol y la luna, los colores del mundo, la oscuridad de la noche. La ventana es donde se encuentran y cruzan el interior con el exterior, uniendo dos mundos y sus elementos. Sueños, recuerdos y fantasías son ventanas a la realidad atemporal de la psique y a la complejidad y potencialidad del soñador. La ventana a la eternidad es una expansión espiritual a través de la cual el alma abordaba la cuestión de la dimensión inconsciente de la psique, el flujo divino dador de autoconocimiento (Ronnberg y Martín, 2011: 564).

En «Habituación», de Tengo una raíz en el aire (Li yidr fi l-hawa', 2001: 11-15), dejados atrás los juegos infantiles, las ventanas de la poetisa aparecen asociadas a la luna (Arango, 1998: 58; Biedermann, 2017: 277-280), cargada de significado femenino, cuyos influjos pueden traducirse como anhelo o deseo:

y mis ventanas desnudas, solo vestidas de una luna

y un hilo de anhelo.

En «Mi sangre que baila te basta», de Tengo una raíz en el aire (Li yidr fi lhawa', 2001: 32-33), la ventana aparece asociada a la desnudez (Biedermann, 2017: 
149), a la posible relación del amado con otra mujer, por lo que Widad le recomienda irónicamente que abra todas las ventanas cerradas:

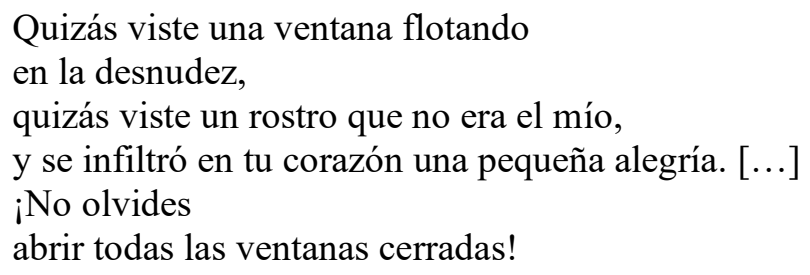

En «Soledad», de Tengo una raíz en el aire (Li yidr fi l-hawa', 2001: 76-78), las ventanas, como espacio abierto al exterior, se asocian a las visiones, al deseo de conectar el mundo interior con el exterior:

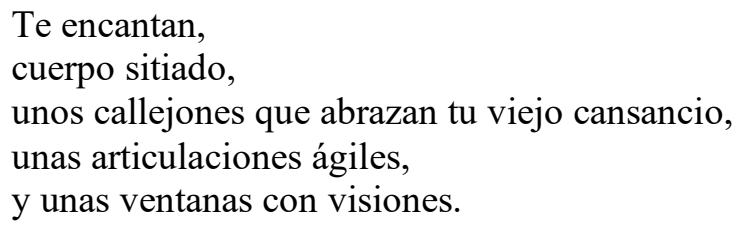

En «Disgusto», de Entre dos nubes (Bayna gaymatayni, 2006: 18-19), la poetisa cierra la ventana al exterior, impidiendo el desarrollo normal del ciclo de la naturaleza y la realización vital de la mujer, simbolizada en esos árboles pequeños sin vida, con un claro predomino de la pulsión de Tánatos (Vegas, 2008: 14-16; Brass, s.d.: 1-4):

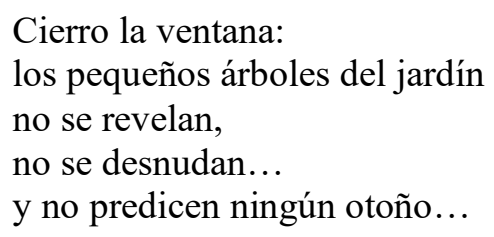

Por el contario, en «Solo tú eres el aire», de Entre dos nubes (Bayna gaymatayni, 2006: 76-77), Widad abre las ventanas al exterior en todas las dimensiones de su realidad, para unir su mundo interior al exterior, predominando la pulsión de Eros como fuerza vital (Valverde, 1998: 120-122):

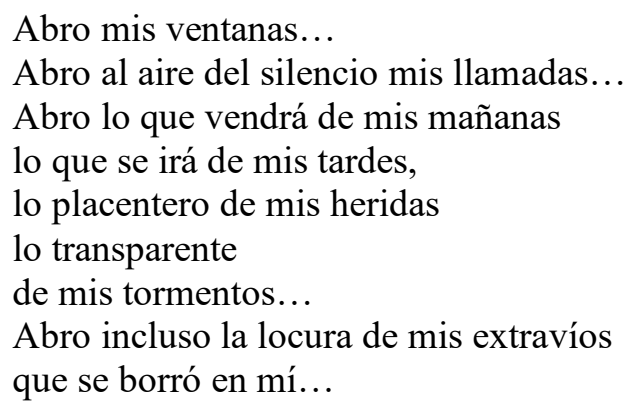

En «Florece en las riberas», de Las abrí a ti (Fatahtu-ha 'alay-ka, 2006a: 8-9), la ventana aparece relacionada con los sueños (Chevalier y Gheerbrant, 2015: 959-966), como procesos llenos de ilusiones y de aspiraciones personales. Al mismo tiempo la ventana sirve para que la poetisa cuestione el legado cultural de los ancianos, representado en un anzuelo que puede capturar esos sueños: 


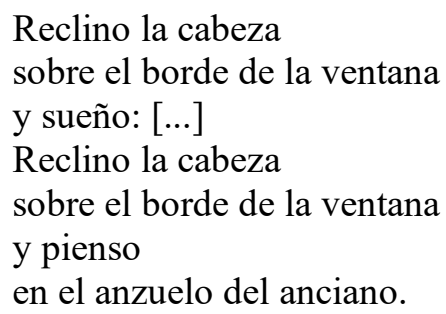

En «Tristeza de las ventanas», de Las abrí a ti (Fatahtu-ha 'alay-ka, 2006a: 1213), las ventanas de la casa de su abuela, que en la infancia de la poetisa brillaban y estaban abiertas al exterior, ahora están tristes, sin más vida que unas flores, mientras que la vida de su abuela sigue encerrada en el interior por una pared que reprime la libertad de acción hacia el mundo exterior, pasando de la pulsión de Eros a la de Tánatos (Tulián, 2006: 6-7):

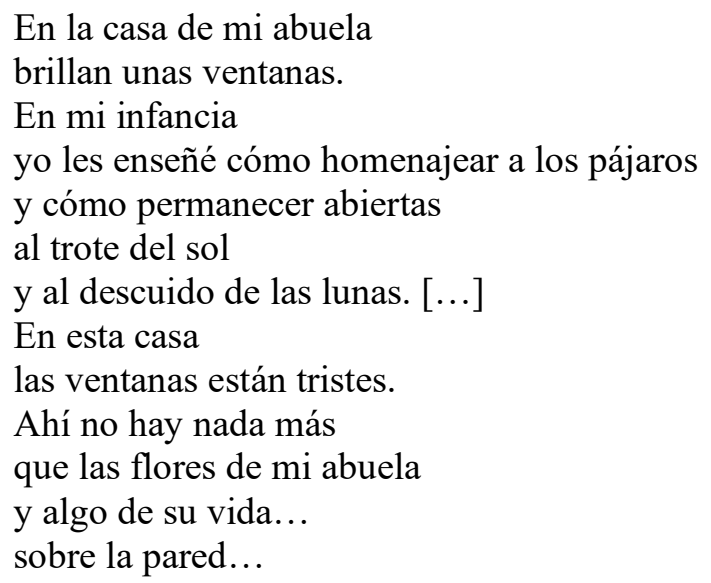

En «Me dijo una flor», de Las abrí a ti (Fatahtu-ha 'alay-ka, 2006a: 14), la flor (Cirlot, 2006: 211-212) aconseja a la poetisa que solo abra sus ventanas a los aspectos positivos de las mañanas del otro (Chevalier y Gheerbrant, 2015: 687):

Haz como yo:

no abras tus ventanas

más que a las mañanas del otro.

En «Cólera», de Las abrí a ti (Fatahtu-ha 'alay-ka, 2006a: 16), la ambición de la ventana es la misma de la poetisa, que desea escapar del mundo de las sombras (Serrano y Pascual, 2012: 283) en que se encuentra:

¿Y cómo me haces habitar ahora

en los territorios de la sombra? [...]

¡Oh, ventana!

Su ambición

es mi ambición.

En «Como si ella amase», de Las abrí a ti (Fatahtu-ha 'alay-ka, 2006a: 18-19), la ventana está abierta al amor, y baila al ritmo de las canciones de la poetisa, que se expresa con plena libertad, primando la pulsión de Eros (Marcuse, 1985: 3-5): 
La ventana bailó

al ritmo de lo que yo cantaba,

como si yo la hubiese preparado para el amor,

como si ella amara.

En «Estado», de Las abrí a ti (Fatahtu-ha 'alay-ka, 2006a: 20), las ventanas, como símbolo de las diversas mujeres, se expresan a través de ideas antitéticas, como llorar/reír, marchitarse/madurar, quejarse/crecer altas...; es decir, unas mujeres se realizan en todos los aspectos de su vida, mientras otras no llevan a cabo sus proyectos, según del ámbito del que procedan. Y la ventana de Widad relincha, emite con fuerza su voz, para reivindicar la liberación de todas las mujeres de las costumbres heredadas:

\author{
Las ventanas lloran. \\ Las ventanas ríen. \\ Las ventanas se marchitan, \\ mientras otras maduran \\ Las ventanas se quejan, \\ mientras otras crecen altas. \\ Cada ventana mantiene \\ el estado del árbol \\ del que desciende. \\ Pero mi ventana \\ relincha.
}

En «Lección», de Las abrí a ti (Fatahtu-ha 'alay-ka, 2006a: 22), Widad vuelve a denunciar las privaciones que sufren muchas mujeres: su propia ventana está iluminada, rodeada de flores, lunas y cielo, es decir, realizada amorosamente, mientras su vecina desconoce el amor:

Mi vecina en el amor

me dijo:

¿Qué son todas estas ventanas iluminadas

en tu cuerpo?

¿Qué son todas estas flores que las rodean?

¿Qué son todas estas lunas?

¿De dónde tienes este cielo?

Mi vecina en el amor

ignora

el amor.

En el breve poema «Crueldad», de Las abrí a ti (Fatahtu-ha 'alay-ka, 2006a: 24), la poetisa considera una crueldad que una mano tosca cierre ventanas y postigos (Ronnberg y Martín, 2011: 380), la apertura al amor, causando heridas en la mujer que aspira a realizarse:

El postigo de la ventana derecha se queja.

¿Qué es esa mano tosca

que la cerró?

Hirió sus sentimientos

poco antes de la llegada de la luna. 
En «El deseo del sol», de Las abrí a ti (Fatahtu-ha 'alay-ka, 2006a: 26-27), Widad se siente especialmente solitaria, al carecer su ventana del deseo del sol y no ser abierta por los vientos, como otras ventanas o mujeres, sino devastada por la tempestad y la ausencia de amor:

¿Quién de nosotras es la más solitaria?

¿Esa ventana a la que le basta el deseo del sol

o yo,

parada cara a cara

con un lirio que me pregunta

qué he hecho con los recuerdos?

¿Quién de nosotras es más serena tras el escalofrío de la noche?

¿Ella,

una ventana que abren los vientos,

o yo,

cuyos tiempos casi los dispersan

las tempestades?

Pero nadie se parece a mí en esta soledad...

En «Guiño», de Las abrí a ti (Fatahtu-ha 'alay-ka. 2006a: 28), la poetisa plantea que en el pasado la mujer consideraba insolente a la luna, porque la relación amorosa se realizaba en la oscuridad; pero las nuevas generaciones, hastiadas, rechazan esa oscuridad y prefieren la insolencia de la luz de la luna (Biedermann, 2017: 277-280):

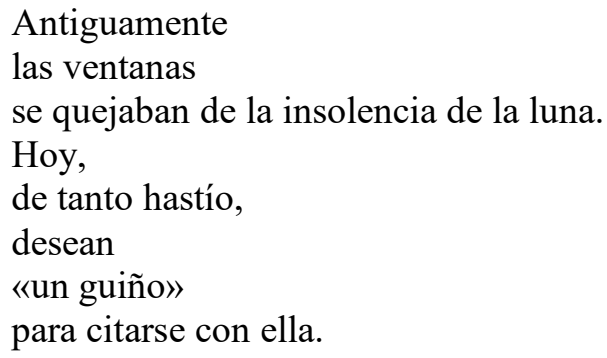

En «Una ventana en el corazón», de Las abrí a ti (Fatahtu-ha 'alay-ka, 2006a: 30), las ventanas son las del corazón de la propia poetisa, que se burlan de su soledad, pues el amado ha desaparecido de su corazón:

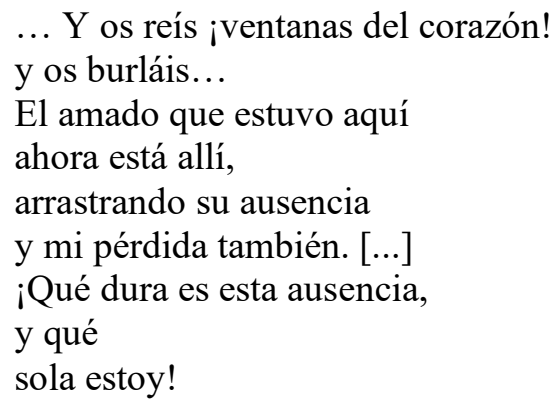

En «Traición», de Las abrí a ti (Fatahtu-ha 'alay-ka, 2006a: 32-33), Widad vuelve a quejarse del abandono y traición del amado, al que había abierto sus ventanas y al que había dedicado sus poemas: 
El cielo azul.

A él abrí mis ventanas.

El cielo diáfano.

A él escribí mis poemas.

El cielo que yo amé

me traicionó

y se marchó.

En «Visión», de Las abrí a ti (Fatahtu-ha 'alay-ka, 2006a: 34), las ventanas de la amada se abren y se entregan al sauce (Chevalier y Gheerbrant, 2015: 916-917), o amado, en una gozosa relación amorosa:

Entre el sauce y la ventana

hay una relación de donación.

Bajo el sauce

los amantes hacen fiesta.

Detrás de la ventana

el amor empieza su marcha.

En «Semejante a mí», de Las abrí a ti (Fatahtu-ha 'alay-ka, 2006a: 36), la nostalgia es el tema que comparten la poetisa y esta ventana cerrada en una habitación lejana; ambas se hacen confidencias tal vez por la pena de verse lejos de la patria, de los familiares o de los amigos, o tal vez por el recuerdo de una pérdida afectiva:

Yo dialogué con ella, y ella dialogó conmigo.

¡Cuánto le revelé a ella

y cuánto me reveló ella a mí!

Esa ventana cerrada

en la habitación lejana.

Nos parecemos en la nostalgia.

En el poema «Entre mi muerte y su vida», de Las abrí a ti (Fatahtu-ha 'alay-ka, 2006a: 42-43), la madre de Widad aparece abriendo cada día las ventanas para aspirar el perfume de la mañana (Chevalier y Gheerbrant, 2015: 687); pero un día esas ventanas permanecieron cerradas, evocando así el terrible impacto que produjo en ella la muerte de su madre:

Mi madre

abría las ventanas al despuntar el alba.

El perfume de la mañana

sembraba en su sangre

una nueva vida.

Cierta mañana

al despuntar el alba

las ventanas siguieron cerradas.

Solo estaba el perfume de la mañana

irradiando en mi sangre

una nueva muerte.

En «Hasta que él dijo», de Las abrí a ti (Fatahtu-ha 'alay-ka, 2006a: 46-47), las ventanas señalan la apertura del amado hacia la poetisa, con la que vivió una relación amorosa muy intensa; pero esas ventanas dejaron de ser suyas cuando el amado la sintió 
lejana, lejanía que bien puede ser entendida como lejanía afectiva o como lejanía en el espacio físico:

Sus ventanas siguieron siendo mías,

para mí sola.

¡Cuánto juró que las mantendría abiertas a mí! [...]

Sus ventanas siguieron siendo mías,

hasta que él dijo:

¡Qué lejos estás!

En «El otoño de la ventana», de Las abrí a ti (Fatahtu-ha 'alay-ka, 2006a: 5051), la ventana agoniza al llegar el otoño; ha pasado el tiempo en que la poetisa gozaba de las mañanas, de la confianza en sí misma, en los demás y en la existencia; pero al llegar el otoño esos aspectos positivos de la mañana se pierden y el corazón de la poetisa agoniza:

Unas mañanas se sucedieron sobre esta ventana, $[\ldots]$

Nada queda

salvo mi corazón,

desde el que espío

una ventana

que agoniza.

En «La juguetona», de Las abrí a ti (Fatahtu-ha 'alay-ka, 2006a: 54-55), Widad califica a la ventana de insolente y de celosa; como ni siquiera una estrella fugaz (Serrano y Pascual, 2012: 113-114), pasajera, se ha ofrecido a la ventana, a la poetisa, causando su soledad y sus suspiros, censura la vinculación erótica entre la noche y la ventana juguetona, alertando al espacio exterior para que no provoque al espacio femenino de la noche a nivel sexual:

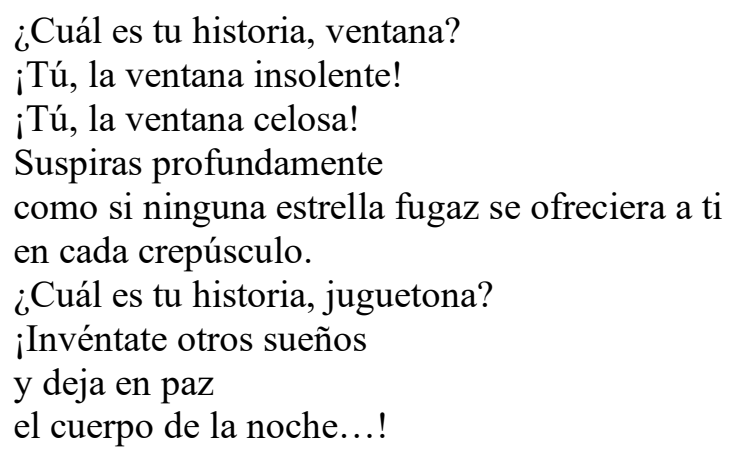

En «En dispersión», de Las abrí a ti (Fatahtu-ha 'alay-ka, 2006a: 56), Widad se identifica con una ventana o mujer, dado que ambas carecen de patria y de alguien que las ame, prevaleciendo la pulsión de Tánatos (Dreussi, 2017: 1-2; Dörr Zegers, 2009: 190-192):

No tienes patria, ventana mía, como yo no tengo amor.

Ambas estamos perdidas en una insoportable dispersión.

Tú estás sin mañana,

y yo estoy $\sin$ tañedor... 
En «La que sabe», de Las abrí a ti (Fatahtu-ha 'alay-ka, 2006a: 58), la poetisa se identifica con las antiguas ventanas de una casa, un barrio o una ciudad en las que ha vivido, para preguntarse quién es ella y la razón de su tristeza, tal vez por las posiciones tradicionales mantenidas sobre la mujer:

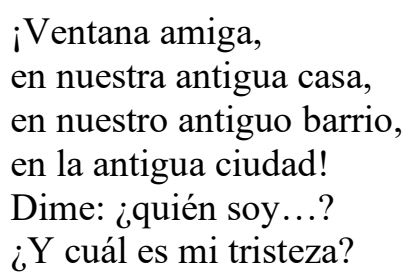

En «La lluvia de la perplejidad», de Las abrí a ti (Fatahtu-ha 'alay-ka, 2006a: 60-61), no hay respuestas a las preguntas que se hace la poetisa sobre la angustia que la llegada de la noche (Serrano y Pascual, 2012: 219) provoca en su corazón y en el de otras mujeres o ventanas:

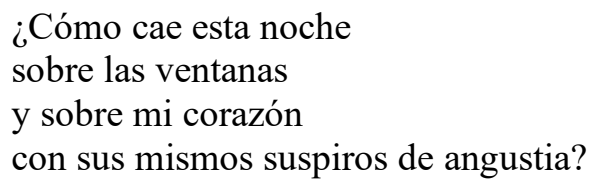

En «Historias del muro», de Las abrí a ti (Fatahtu-ha 'alay-ka, 2006a: 62-63), el muro representa el elemento masculino (Chevalier y Gheerbrant, 2015: 738-739) y la ventana el elemento femenino de una historia amorosa, en la que el muro protege a la ventana de la lluvia y del sol para que no sufra; pero el muro siente celos de la charla de la ventana con la tarde:

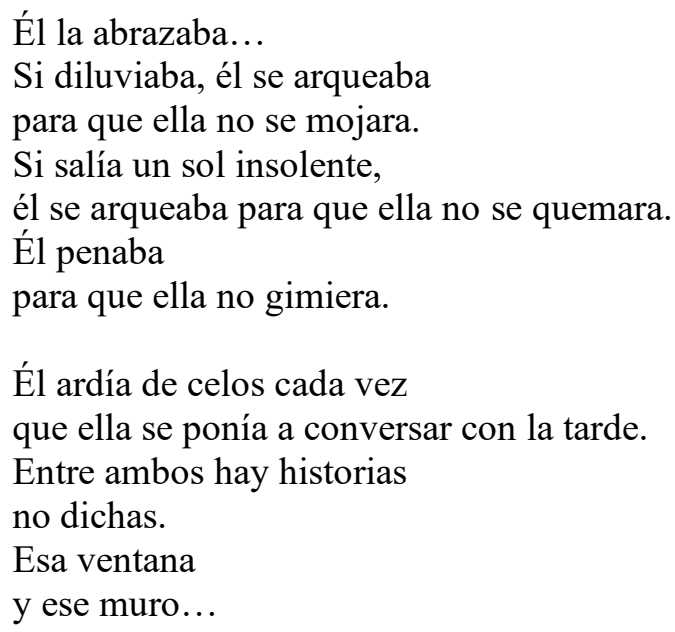

En «Árbol de amor», de Las abrí a ti (Fatahtu-ha 'alay-ka, 2006a: 64-65), Widad se identifica con una ventana que vive una erótica relación con su amante, la noche (Chevalier y Gheerbrant, 2015: 753-754), a la que espera en silencio si se retrasa:

La noche es su amante. Esta ventana penetra en el silencio cada vez que él se retrasa. [...]

¿Y qué si yo creyera que no soy más que esa ventana? 
En «Vi todo eso», de Las abrí a ti (Fatahtu-ha 'alay-ka, 2006a: 68-69), la ventana se ofrece a la poetisa como apertura al espacio físico exterior para conectarla con multitud de aspectos del mundo que la rodea:

El mar agitado.

La colina sin atardecer.

El ave bañándose en un arco iris.

El bosque con sus arbustos de polvo.

El loto enamorado.

Las olas fascinantes.

La mano allí estremecida.

La lluvia transparente.

Los amantes purificándose. [...]

El hombre disculpándose ante una nube virgen.

La mujer oponiéndose a varios imposibles.

Los besos calentando el pecho del mundo.

Desde mi ventana...

vi todo esto.

En «Alrededor de su fuego», de Las abrí a ti (Fatahtu-ha 'alay-ka, 2006a: 7677), en los primeros versos el amado abre las ventanas y balcones de su amada, reúne bellas estrellas a su alrededor y le dibuja unas expectativas de futuro transparentes. Pero no recuerda que el fuego (Chevalier y Gheerbrant, 2015: 511-514) había quemado a la mariposa en el juego erótico, cortando sus alas. Por ello la relación amorosa de la poetisa se mueve entre la certeza del juego amoroso y la incertidumbre que la atormenta, sin renunciar a unas expectativas que ve lejanas:

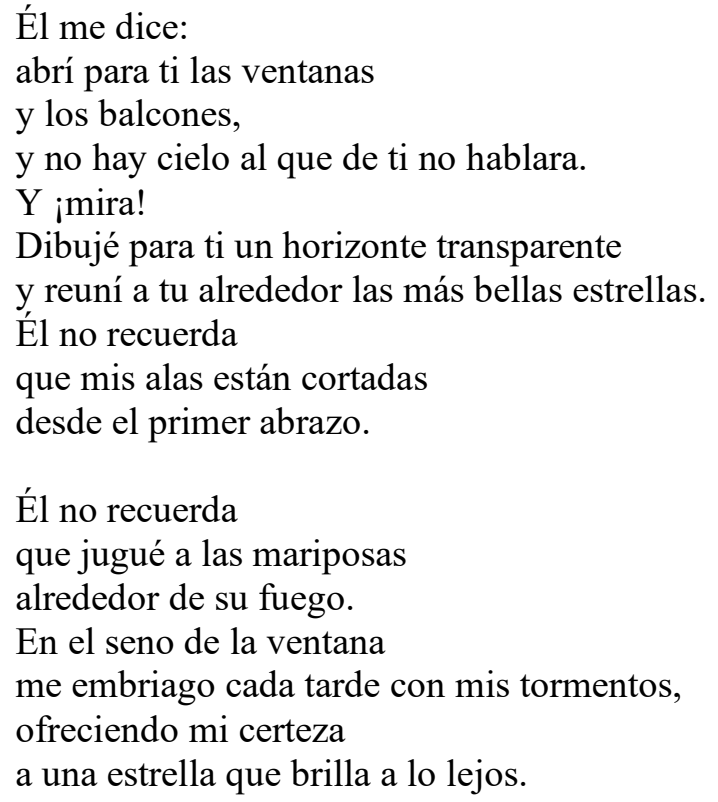

En «Como una gota en el alma», de Las abrí a ti (Fatahtu-ha 'alay-ka, 2006a: 78), la ventana representa a la poetisa que se veía hermosa y solitaria en el pasado, y a pesar de alejarse de ese pasado siempre acaba volviendo a él:

No me dirijo a la ventana solitaria.

No me dirijo a la ventana hermosa. 
La ventana lejana.

Cada vez que me alejo

no veo más que esta ventana,

y no me dirijo más que a ella...

En «Dedicatoria», de Tempestad en el cuerpo (Zawba'a fi yasad, 2008: 5, 7-8), la ventana representa un espacio positivo de apertura al exterior para Widad, que invita a las frustraciones de su vida a que la abandonen, pues quiere vivir tras un periodo nefasto de su vida:

La que regresa de su muerte debe atreverse a vivir. [...]

La abubilla frustrada, a abandonar mi ventana.

En el fragmento 3 de «Introducción a las profundidades del amor», de $M e$ distraigo con esta vida (Alhu bi-hada l-'umr, 2014: 23-32), la ventana aparece relacionada con el polvo. Sacudirse el polvo de las sandalias simboliza el abandono total del pasado (Chevalier y Gheerbrant, 2015: 847), en este caso la ruptura con el antiguo amado:

En tu dolor a menudo vi la transformación de la visión, como si fuera la transformación del aire. En tu pérdida no tenía yo una única noche, sino que tenía oscuridades. En tu pérdida a menudo el viento me hizo desviarme hacia los límites de tu desierto, y te vi desde la ventana del polvo.

En la estrofa 17 de «Dióxido del dolor», de Me distraigo con esta vida (Alhu bihada l-'umr, 2014: 51-64), la poetisa se dirige a un tú masculino, y le aconseja que si el dolor le viene de noche deje entreabierta su ventana para que vuele:

¡Coge tu dolor como una mariposa si te viene de noche,

y deja tu ventana medio abierta!

Quizás vuele.

¡No lo veas como una guillotina!

¡Míralo como un insecto nocturno!

¡Percíbelo con tu muerte!

¡Contémplalo... por la rendija de la ventana... volando...!

En «Él dijo», de Me distraigo con esta vida (Alhu bi-hada l-'umr, 2014: 133), Widad parece identificarse con la función del poeta, cuya alma se asemeja a una ventana desde la que es capaz de desvelar los lejanos secretos:

El poeta es un observador.

Es como si su ojo estuviese en su corazón,

como si su alma

fuese una ventana sobre los velos,

sobre los lejanos secretos...

En «Una antigua agitación», de Me distraigo con esta vida (Alhu bi-hada l- 'umr, 2014: 137-145), subtitulado «Los siete enanitos y el amor», Widad añora su infancia, en la que el niño al que amaba la llamaba silbando bajo su ventana y ella bajaba corriendo a su encuentro, algo que ya de mayores no volvería a repetirse: 
No me llamarás desde debajo de la ventana de mi cuarto con tu dulce silbido.

No bajaré la escalera con la prisa del amor que crece en los miembros como un fuego hambriento.

\section{ESTUDIO CUANTITATIVO DEL LÉXICO}

El estudio cuantitativo del léxico se ha realizado sobre un total de 23.596 palabras, recogidas en los 251 poemas que integran los 6 poemarios de la poetisa Widad Ben Musa objeto de esta investigación, referenciados en árabe y partir de la traducción al castellano.

Para ello se ha realizado una base de datos diseñada al efecto para su almacenamiento y su posterior análisis en unas hojas de cálculo donde se realizan las distintas operaciones que luego se indicarán. Para que el estudio tenga sentido, es necesario que las palabras tengan un valor mínimo de aparición, eliminando las de menor frecuencia, ya que no presentan un valor significativo, así como las de frecuencia muy elevada si son «palabras herramienta» por su función gramatical. Por tanto, se han descartado la mayoría de las palabras con una frecuencia absoluta superior a $400 \mathrm{y}$ otras con frecuencia inferior a 3 por considerar su aparición como algo esporádico.

Para el análisis estadístico de este trabajo se han seguido dos métodos distintos:

\section{Método Campillos-Ueda}

Los conceptos estadísticos, o herramientas descriptivas, más importantes utilizados por Campillos-Ueda (2015) son los siguientes: Frecuencias absolutas. I Frecuencias relativas (normalizadas por mil). / Rangos de frecuencias. / Dispersión lineal media. / Rangos de dispersión. / Valor de uso. / Rangos de uso.

- Frecuencia absoluta de cada lema o vocablo: es el número total de apariciones de dicho vocablo a lo largo de toda la obra analizada. Se obtiene mediante conteo del número total de apariciones de cada símbolo en los poemas analizados.

- Frecuencia relativa normalizada: nos muestra la relación entre el vocablo analizado con respecto al número total de vocablos. Se obtiene al dividir el número de apariciones de un símbolo, es decir, su frecuencia absoluta, entre el número total de vocablos analizados, para estimar su importancia frente a los demás y multiplicada por mil.

- Rangos de frecuencias: nos van a permitir agrupar los lemas según su aparición a lo largo de los textos. En primer lugar hay que decidir el número de rangos en el que queremos subdividir el total de términos analizados, y posteriormente adscribir el vocablo de mayor frecuencia al rango superior. Esto nos permite agrupar y traducir a un lenguaje más coloquial los resultados obtenidos mediante el estudio de frecuencias. Para ello se han establecido 3 intervalos que indican la frecuencia de aparición: Baja (entre 0 y 1); Media (entre 1 y 2); Alta (entre 2 y 3 )

Para establecer el criterio de pertenencia a uno u otro intervalo de frecuencias se ha usado la siguiente operación logarítmica que nos simplificará los cálculos: debemos calcular la base del logaritmo a, que nos permita encasillar el símbolo con mayor frecuencia en el intervalo superior; llamando fmax a la frecuencia máxima $\log _{a} f m a x=3$ ( $\mathrm{n}^{\mathrm{o}}$ intervalos); la base del logaritmo queda establecida como $\mathrm{a}=\mathrm{fmax}^{1 / 3}$

En este estudio se ha considerado suficiente la agrupación de los términos en tres rangos de frecuencias, donde las frecuencias entre 0 y 1 corresponden a una frecuencia 
baja, las comprendidas entre 1 y 2 a una frecuencia media y las superiores a 2 como alta frecuencia.

- Dispersión Lineal Normalizada (Dispersión léxica): es una de las medidas más usadas en lexicografía y refleja la distribución de la frecuencia a lo largo de los textos. Esta medida de dispersión es un estadístico necesario, ya que nos da información sobre aquellos términos que aparecen de manera esporádica frente a aquellos que lo hacen a lo largo de toda la obra.

Se obtiene dividiendo el número total de vocablos de la obra entre el número de ocurrencias del símbolo (frecuencia de aparición): $\mathrm{dm}=\mathrm{N} / \mathrm{f}$ (en que $\mathrm{dm}=$ dispersión media; $\mathrm{N}=$ número total de vocablos, $\mathrm{y} \mathrm{f}=$ frecuencia absoluta del símbolo estudiado).

Para el cálculo de la dispersión lineal normalizada (DLN) son necesarios unos cálculos intermedios: en primer lugar, calculamos la distancia acumulada mediante la sumatoria de las diferencias entre la distancia de cada aparición y la dispersión media, al cuadrado.

- La desviación estándar: para el cómputo de la desviación estándar normalizada (DEN) hemos de contar en primer lugar el valor medio de las distancia mediante la ecuación y así poder enumerarla. De esta manera la dispersión lineal normalizada se calcula como la diferencia entre 1 y la desviación estándar normalizada $\mathrm{DLN}=1-\mathrm{DEN}$. Esto nos da información sobre las distancias de aparición del símbolo a lo largo de los textos analizados, de manera que un valor próximo a 1 indica una frecuencia regular de aparición, mientras que un valor próximo a 0 indica una ocurrencia de muy baja regularidad.

Se establecen 3 rangos de dispersión cuyos valores estarán distribuidos entre $0 \mathrm{y}$ 1: el modo de acomodar cada vocablo en un determinado rango es multiplicar el valor de la dispersión lineal normalizada por el número de rangos y redondear el resultado para obtener la parte entera.

- El valor y los rangos de uso: permiten la caracterización de léxicos nucleares. El Valor de uso se obtiene al multiplicar la frecuencia absoluta del símbolo por la Dispersión Lineal Normalizada para establecer los términos de mayor importancia distribuidos uniformemente. $U=F$ x DLN. El Rango de uso se obtiene de igual forma que los rangos de frecuencias, es decir, calculando el logaritmo en la base previamente calculada para los rangos de frecuencia.

\section{Método de Bellón Cazabán}

Para el estudio del léxico siguiendo el modelo de Bellón Cazabán (1973), se han tenido en cuenta las frecuencias absolutas y las frecuencias relativas de los términos, las cuales rectifican en ocasiones a las absolutas, así como las frecuencias medias para homogeneizar los resultados obtenidos en cada poemario, ya que el número de palabras oscila desde algo más de 400 hasta un valor superior a 4.500 .

Por último, se va a estudiar cuantitativamente el símbolo de la ventana al ser el eje central de Las abri a ti.

Para el primer método utilizado, los resultados obtenidos se presentan en la siguiente tabla, donde apreciamos los valores de las frecuencias que nos van a permitir el estudio del resto de estadísticos. 


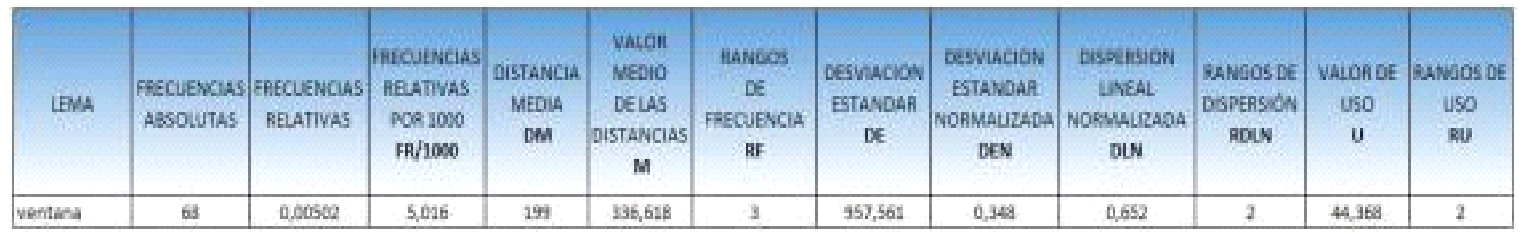

Según los resultados, vemos que el vocablo «ventana» tiene una frecuencia de aparición elevada en los textos, incluyéndose en el rango de altas frecuencias.

$\mathrm{Su}$ distancia media es de casi 200 palabras, es decir, para que tuviese una distribución homogénea a lo largo de todos los textos debería aparecer ese número de palabras, y como podemos observar presenta un valor medio de distancia de 337 aproximadamente, no alejándose demasiado de esta.

La Dispersión que muestra el estudio, sin embargo, nos indica que la distribución no es homogénea, sino que debe presentar unas altas concentraciones en algunos libros, y muy bajas en otros (recordemos que una dispersión lineal próxima a 1 indica una distribución homogénea).

Ayudándonos del estudio de Bellón Cazabán, vemos que esta distribución es la mostrada en la siguiente tabla, que muestra una frecuencia de aparición muy elevada en Las abrí a ti, donde se concentra prácticamente su aparición, y es nula o casi nula en el resto de los textos.

\begin{tabular}{|r|l|r|r|}
\hline \multicolumn{1}{|c|}{$\begin{array}{c}\text { LENTANA } \\
\text { total vocablos }\end{array}$} & f. absoluta & f. relativa \\
\hline 3743 & 1.-Tengo una raiz en el aire & 4 & 1,07 \\
\hline 1702 & 2.-Entre dos nubes & 2 & 1,18 \\
\hline 926 & 3.-Las abrí a ti & 55 & 59,40 \\
\hline 2109 & 4.-Tempestad en el cuerpo & 1 & 0,47 \\
\hline 415 & 5.-Estuve a punto de perder mi narcisismo & 0 & 0,00 \\
\hline 4661 & 6.-Me distraigo con esta vida & 6 & 1,29 \\
\hline 13556 total apariciones (frecuencia absoluta) & $\mathbf{6 8}$ & $\mathbf{6 3 , 4 0 0}$ \\
\hline & frecuencia total absoluta & $\mathbf{5 , 0 1 6}$ & \\
\hline & frecuencia total relativa & $\mathbf{1 0 , 5 6 7}$ & \\
\hline
\end{tabular}

El gráfico de frecuencias muestra su presencia casi nula en la mayoría de los textos, quedando muy por debajo de la frecuencia total relativa, excepto en Las abri a ti donde se aprecia claramente su importancia, mostrando un máximo de casi 60 puntos. 


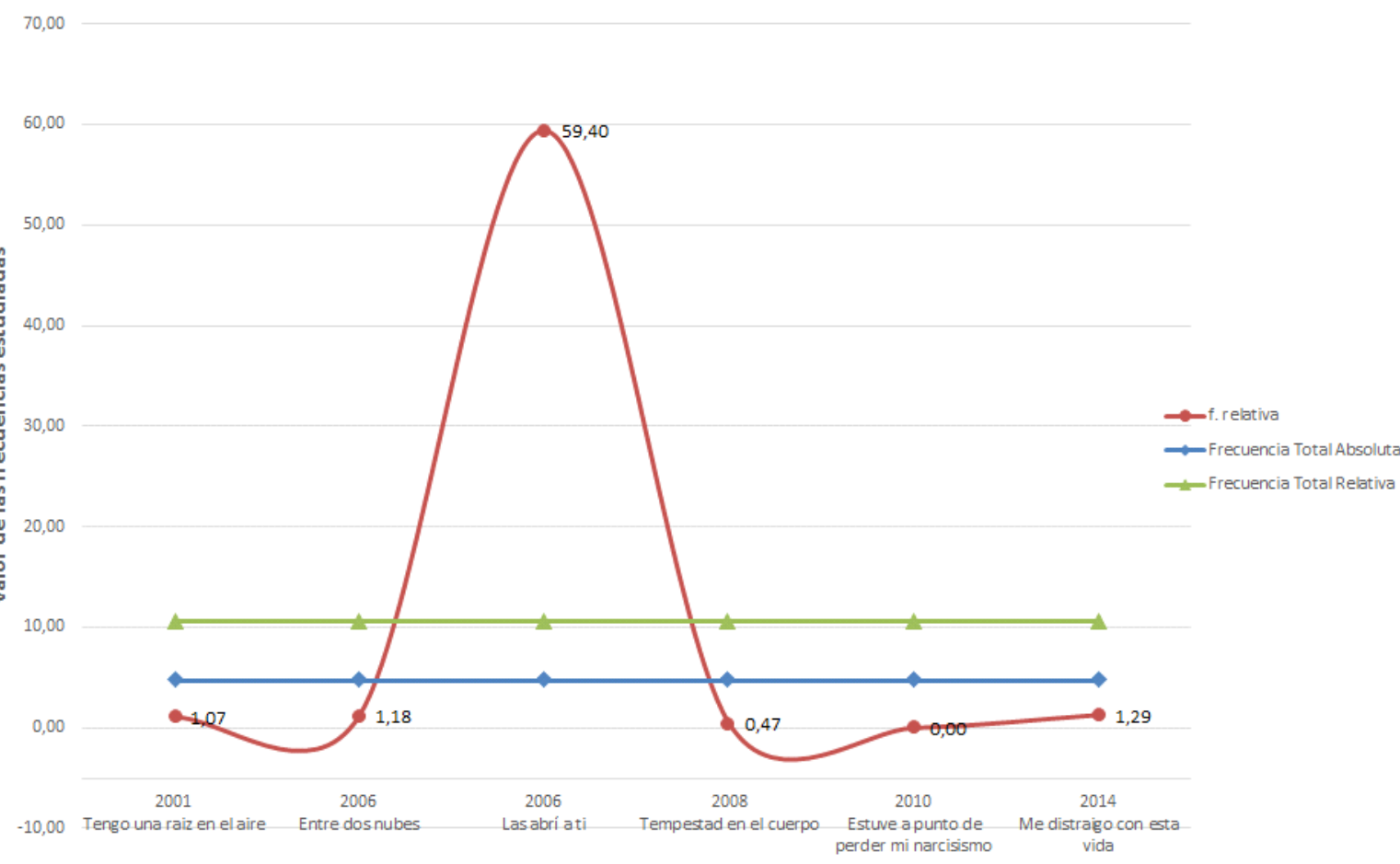

Y lo mismo puede observarse en la siguiente tabla y en los dos gráficos posteriores

\begin{tabular}{|l|c|c|c|c|c|c|c|}
\hline & $\begin{array}{c}2001 \\
\text { Tengo una } \\
\text { raiz en el aire }\end{array}$ & $\begin{array}{c}2006 \\
\text { Entre dos } \\
\text { nubes }\end{array}$ & $\begin{array}{c}2006 \\
\text { Las abrí a ti }\end{array}$ & $\begin{array}{c}2008 \\
\text { Tempestad } \\
\text { en el cuerpo }\end{array}$ & $\begin{array}{c}2010 \\
\text { Estuve a punto } \\
\text { de perder mi } \\
\text { narcisismo }\end{array}$ & $\begin{array}{c}2014 \\
\text { Me distraigo } \\
\text { con esta vida }\end{array}$ & $\begin{array}{c}\text { frecuencia } \\
\text { absoluta }\end{array}$ \\
\hline ventana & 4 & 2 & 55 & 1 & & 6 & 68 \\
\hline
\end{tabular}




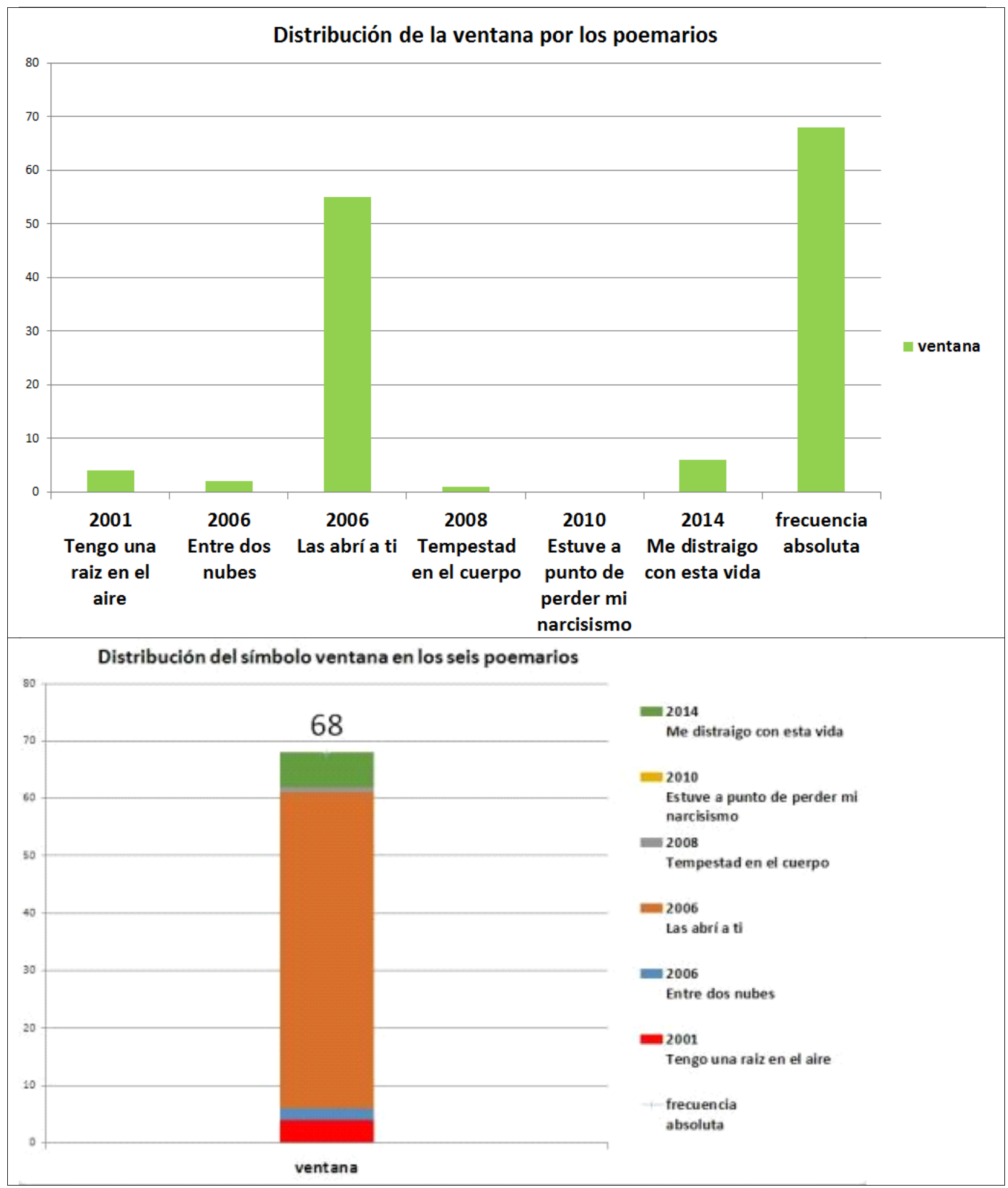




\section{CONCLUSIONES}

La ventana es un umbral transparente, una abertura en una pared donde se encuentra el interior con el exterior, pero a menudo simboliza a la mujer, sus anhelos y su imaginación. Mientras es la protagonista en Las abrí a ti (2006a) y no aparece en Estuve a punto de perder mi narcisismo (2010), tiene una frecuencia baja en el resto de los poemarios. En esos poemas prima la pulsión de Eros, mientras en otros se equilibra con la de Tánatos o esta la supera.

En Tengo una raíz en el aire (2001) aparece en tres poemas. En el primero las ventanas aparecen asociadas a la luna, cuyos influjos pueden traducirse como deseo; en el segundo la ventana se asocia a la desnudez y a la posible relación del amado con otra mujer; y en el tercero las ventanas se asocian a las visiones, al deseo de conectar el mundo interior con el exterior.

En Entre dos nubes (2006) aparece en dos poemas. Si la poetisa cierra su ventana al exterior, impidiendo su realización vital; luego abre las ventanas al exterior para unir a él su mundo interior.

En Las abrí a ti (2006a) la ventana aparece en todos los poemas. En catorce poemas prevalece la pulsión de Tánatos, unos expresando la realidad del desamor del amado; otros traduciendo nostalgia, agonía y angustia de la noche ante los acontecimientos de la realidad exterior, o criticando la ventana cerrada en el pasado en casa de su abuela o la ventana que se cierra al morir su madre; y en tres de ellos se censura una realidad de género negativa, con los respectivos reproches de la realidad exterior, de la falta de patria y de amor, de la tristeza que producen las posiciones tradicionales mantenidas hacia la mujer. Sin embargo, en el resto de los poemas prevalece la pulsión de Eros, reflejando una realidad amorosa plena, exponiendo sueños o expectativas que la ilusionan, abogando por la otredad y por un espacio libre iluminado por la luna de la noche, e incluso afrontando el fracaso y atreviéndose a volver a vivir; por otro lado, en otros dos poemas se manifiestan a la vez Eros y Tánatos en las distintas realidades de género, bien a través de imágenes antitéticas de mujeres que lloran o ríen, que se marchitan o maduran, que se quejan o crecen altas, bien expresando el amor en las ventanas iluminadas en el cuerpo de la poetisa frente al desamor que padece su amiga de la vecindad.

En Tempestad en el cuerpo (2008) aparece solo en un poema, en que la ventana representa la apertura al exterior de la poetisa, que invita a las frustraciones de su vida a que la abandonen, pues quiere vivir tras el desamor.

En Me distraigo con esta vida (2014) aparece en cuatro poemas. En el primero, la ventana, asociada al polvo, simboliza el abandono total del pasado, del antiguo amado; además la poetisa aconseja a un tú masculino que, si el dolor le viene de noche, deje entreabierta su ventana para que vuele; luego se identifica con un poeta, cuya alma se asemeja a una ventana desde la que es capaz de desvelar los lejanos secretos; y al final añora su infancia, en la que el niño al que amaba la llamaba silbando bajo su ventana y ella bajaba corriendo a su encuentro. 
Arango, Manuel Antonio (1998) [1995], Símbolo y simbología en la obra de Federico García Lorca, Madrid, Fundamentos.

Beck, Ulrich (2009), El Dios personal: la individualización de la religión y el «espiritu» del cosmopolitismo, Barcelona, Paidós Ibérica.

Bellón Cazabán, J. Alfredo (1973), La poesía de Luis Cernuda. Estudio cuantitativo del léxico de «La realidad y el Deseo», Granada, Universidad de Granada.

Biedermann, Hans (2017), Diccionario de símbolos, Barcelona, Paidós Ed. Espasa Libros, S.L.

Binmusà, Widad (2001), Li yidr fi l-hawa'. Si 'r, Rabat, Mansurat Wizarat al-Taqafa wa-l-Ittisal / Matba'at Dar al-Manahil.

Bin Musà, Widad / Ben Moussa, Ouidad (2006), Bayna gaymatayni. Si'r / Entre deux nuages. Poème, ed. bilingüe, trad. francesa Yalal al-Hakmawi, Rabat, Editions Marsam.

Binmusà, Widad / Ben Moussa, Ouidad (2006a), Fatahtu-ha 'alay-ka. Si 'r wa-Suwar / Je les ai ouvertes sur toi. Poèmes \& potos, trad. francesa y prefacio 'Abd al-Rahman Tankul, Rabat, Editions Marsam.

Binmusà, Widad (2008), Zawba'a fi yasad. Si 'r, Al-Ribat, Mansurat Marsam, Matba'at alNayah al-Yadida.

Binmusà, Widad (2010), Kidtu afqidu naryisiyati. Si ‘r, Dimasq, Ward al-Tiba'a wa-1-Nasr wa1-Tawzi‘.

Binmusà, Widad (2014), Alhu bi-hada l-'umr, Dar Tubqal li-1-Nasr, Matba'at al-Nayah alYadida, Al-Dar al-Bayda'.

Brass, Ana Lucía (s/f.), Eros y Tánatos, una tensión inevitable, Instituto Glaux, Capital Federal, $<$ http://www2.ib.edu.ar/becaib/bib2004/Finalistas/AnaBrass.pdf $>$.

Campillo Llanos, Leonardo e Hiroto Ueda (2015), «Frecuencias y dispersión léxicas en textos médicos divulgativos en español», Ibérica, 30, pp. 61-84.

Chevalier, Jean, y Alain Gheerbrant (2015), Diccionario de los símbolos, Barcelona, Herder.

Cirlot, Juan Eduardo (2006), Diccionario de símbolos, Madrid, Siruela.

Del Amo, Mercedes, Juan Marsá y Rafael Ortega (2008), Escritores Marroquíes Contemporáneos, Alcalá la Real, Alcalá Grupo Editorial.

Dörr Zegers, Otto (2009), «Eros y Tánatos», Salud Mental, XXXII, 3, pp. 187-197,

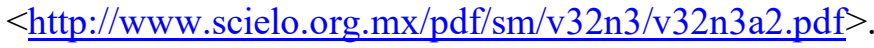

Dreussi, Verónica (2017), «La cura a través del amor hoy. Entre Eros y Tánatos», en S. de Grazia (presidencia), XXXIX Simposio Anual «El Amor», Buenos Aires, Asociación Psicoanalítica de Buenos Aires, <www.apdeba.org/wp-content/uploads/ContribucionVeronicaDreussi-2017.pdf>.

Echchaoui, Bouchrail, y Encarnación Sánchez (2017), «Entrevista a Widad Ben Musa», Revista Literaria Penélope: evolución histórica y literaria desde la antigüedad, 5, pp. 3-6.

Jiménez Delgado, María (2012), La generación puente: la educación de las jóvenes de origen marroquí: un estudio sociológico, Tesis doctoral, Alicante, Departamento de Sociología I. Universidad de Alicante.

Marcuse, Herbert (1985), Eros y civilización, Buenos Aires, Biblioteca Ariel SudamericanaPlaneta, $<$ https://omegalfa.es/downloadfile.php?file=libros/eros-y-thanatos.pdf $>$.

Ruiz de Almodóvar, Caridad (2007), «La legislación de la familia en los países árabes», $E l$ nuevo orden mundial y el mundo islámico, 65, pp. 269-291, $<$ http://www.jstor.org/stable/41325078>.

Ronnberg, Ami, y Kathleen Martin (2011), El libro de los símbolos. Reflexiones sobre las imágenes arquetípicas, trad. Isabel Saval Pou, Pablo Ripollés Arenas y Julia Gara Lecuona Allende, Madrid, Taschen.

Serrano Simarro, Alfonso, y Álvaro Pascual Chenel (2012), El libro de los símbolos, Madrid, Editorial Libsa.

Touraine, Alain (2007), El mundo de las mujeres, Barcelona, Paidós. 
Tulián, Silvia (2006), «De la vida y la muerte -sobre Eros y Tánatos-. Lo sublimatorio», Congreso Argentino de Psicoanálisis. APM, Mza., $<$ https://www.aacademica.org/silvia.m.tulian/2.pdf $>$.

Valverde, Estela (1998), «Eros y Tanatos: Dos expresiones de un deseo propio», Hispanoamérica, XXVII, 79, pp. 113-124.

Vegas, Irene (2008), «La tensión Eros/Tánatos en la obra poética de César Vallejo: un estudio hermenéutico-psicoanalítico», Revistas de investigación UNMSM-Escritura y Pensamiento, XI, 22. 